\title{
Publisher Correction: Salt and potassium intake evaluated with spot urine and brief questionnaires in combination with blood pressure control status in hypertensive outpatients in a real-world setting
}

Masanobu Yamazato - Atsushi Sakima - Akio Ishida - Kentaro Kohagura - Tetsutaro Matayoshi - Takeshi Tana • Masahiro Tamashiro • Yoshio Hata · Tamayo Naka • Yoshito Nakamura • Yusuke Ohya

Published online: 31 August 2021

(C) The Japanese Society of Hypertension 2021

Correction to: Hypertension Research https://doi.org/10.1038/s41440-021-00707-0 published online 3 August 2021
In the version of this article initially published online, owing to a typesetting error, the first letter of Abstract was missing. The first word should read "Reducing".

The original article has been corrected. 